\title{
Qualitative and Quantitative Ultrastructural Analysis of the Mitochondria from Adrenal Gland Cortex Under the Action of Viperidae family Snake Venoms
}

\author{
Análisis Ultrastructural Cualitativo y Cuantitativo de la Mitocondria de la Glándula \\ Adrenal Bajo la Acción de los Venenos de Serpientes de la Familia Viperidae
}

Héctor J. Finol ${ }^{1}$; Estefanie García ${ }^{1}$; Roschman González ${ }^{1}$; Elda E. Sanchez ${ }^{2}$ \& Alexis Rodríguez-Acosta ${ }^{3}$

FINOL, H. J.; GARCÍA, E.; GONZÁLEZ, R.; SANCHEZ, E. E. \& RODRÍGUEZ-ACOSTA, A. Qualitative and quantitative ultrastructural analysis of the mitochondria from adrenal gland cortex under the action of Viperidae family snake venoms. Int. J. Morphol., 38(5):1271-1280, 2020.

SUMMARY: The Viperidae venoms are composed of a mixture of constituents with enzymatic and non-enzymatic actions, which act on ultrastructural components of cells and tissues. Here, the number of mitochondria, mitochondrial area and the number of mitochondrial cristae from adrenal glands cortex treated with snake venoms were tested after 3, 6 and 24 hours of venom injections. The mitochondria quantitative changes showed a statistically significant decrease, in the number of mitochondria past 3,6 and $24 \mathrm{~h}$. There was an increase in the mitochondrial area after $6 \mathrm{~h}$, where Crotalus vegrandis venom did not present significant differences with Crotalus pifanorum or Bothrops venezuelensis venoms. After $24 \mathrm{~h}$, there was an escalation of mitochondrial area in all tested venoms. The number of mitochondrial cristae after $3 \mathrm{~h}$ did not present important differences with the control treatment. After $6 \mathrm{~h}$, the number of mitochondrial cristae initiated to decrease under the activities of the 3 venoms action, until $24 \mathrm{~h}$ of observation. In the qualitative observations it was possible to witness an intense damage of the mitochondria, with loss and swelling of membranes, disappearance of cristae and the appearance of myelin figures, which started at $3 \mathrm{~h}$ after the Crotalus and Bothrops venoms injections. These damages probably were due to cytotoxic effects of phospholipases, metalloproteases and/or other proteolytic activities present in Viperidae snake venoms, being more evident in Crotalus venoms. As far as we know, these results define a novel finding that suggest that Viperidae snake venoms are extremely toxic to mammalian mitochondria.

KEY WORDS: Adrenal gland; Bothrops venezuelensis; Cristae; Crotalus pifanorum; Crotalus vegrandis; Mitochondria; Venom.

\section{INTRODUCTION}

Active modifications of mitochondrial structure and function regulate cellular activities. Transmission electron microscopy (TEM) can be used to obtain micrographs of mitochondria with very high resolution, but the mitochondrial ultrastructure is sometimes simply deformed during the processing of the sample. Here, a method was used that preserves the mitochondrial membrane structure of the gland adrenal cells obtained by TEM. This methodological instrument has been employed to define and assess the internal ultrastructure of mitochondria, in order to obtain higher magnifications or resolutions than the ones provided by light microscopy. Processes for the identification of mitochondria from the adrenal cortex and medulla, from animals inoculated with natural toxins, or purified snake venoms have been previously described (Rodríguez-Acosta et al., 2000; Rodriguez-Acosta et al., 2003; Sanchez et al., 2018). Additionally, TEM is possibly the optimum methodology to detect active variations in mitochondrial membranes and cristae during cell outcome alterations such as differentiation (Cho et al., 2006). Conservation of the intrinsic structure of mitochondria is a challenge because of its physiological command in reacting to fluctuations in the microenvironment. As it is known, mitochondrial ultrastructure is susceptible to osmolarity variations, acidity, temperature variants, and ion concentrations (Waring et al., 1982; Lebowitz et al., 1996).

${ }^{1}$ Electron Microscopy Centre, Faculty of Sciences, Universidad Central de Venezuela, Caracas, Bolivarian Republic of Venezuela. ${ }^{2}$ National Natural Toxins Research Center, Department of Chemistry, Texas A\&M University-Kingsville, Kingsville, Texas, USA.

${ }^{3}$ Laboratory of Immunochemistry and Ultrastructure, Anatomical Institute, Universidad Central de Venezuela, Caracas, Bolivarian Republic of Venezuela. 
Since the effects of the Viperidae venom occur in a short period of time (Sanchez et al., 2014), a kinetics study of adrenal gland cortex from injected mice later than 3,6, and $24 \mathrm{~h}$ was chosen, considering an approximate sequence time, in which the mitochondrial alterations happen.

In this work a collection of mitochondrial damages was observed, which could clarify the pathological ultrastructural features, as well as the clinical signs regarding the mitochondrial adrenal gland injuries caused by Viperidae venom accidents. To our knowledge, these results represent the first time tracking ultrastructural description of severe damage of the mice adrenal gland mitochondria triggered by Viperidae venoms.

\section{MATERIAL AND METHOD}

Snakes. The "tigra mariposa" (Bothrops venezuelensis), black rattlesnake (Crotalus pifanorum) and uracoan rattlesnake (Crotalus vegrandis) specimens were obtained from the Waraira Repano mountains, at the north of Caracas city, Parmana Town (Guárico state), and Uracoa (Monagas state) of the Bolivarian Republic of Venezuela, respectively (Pifano, 1961). Six adult snakes of both sexes, from each species were kept at the Serpentarium of the Tropical Medicine Institute of the Universidad Central de Venezuela (Caracas, Venezuela).

Venom collection. The venoms were obtained by letting the snakes bite into a para-film ${ }^{\circledR}$ stretched over a non-reusable plastic cup. The sample was centrifuged (500×g for $15 \mathrm{~min})$, and filtered through a $0.45 \mu \mathrm{m}$ filter under positive pressure. The venoms were frozen at $-80{ }^{\circ} \mathrm{C}$, lyophilised and maintained at $-30{ }^{\circ} \mathrm{C}$ until used.

Mice. Ultrastructural adrenal gland analyses were performed using NIH mice (18-22 g), purchased from the Animal House of the National Institute of Hygiene "Rafael Rangel", Caracas, Venezuela. Animals were provided with water and food ad libitum, until used.

Ethical approval. For the purpose of this study, the project was accepted by the Institute of Anatomy Ethical Committee of the Universidad Central de Venezuela (October 01, 2018), under certification number: \# 01-10-18, supported in the norms from the ARRIVE (EU Directive 2010/63/EU) for animal experiments guidelines, in accordance with the U.K. Animals (Scientific Procedures) Act, 1986 and associated guidelines. The investigation queries requested, technical methods selected, and conclusions accomplished are the authors' complete responsibility.
Preparation of specimens from adrenal gland cortex for transmission electron microscopy (TEM) (qualitative study). Adrenal glands from envenomed $(n=9)$ and control mice $(n=3)$ were employed for TEM studies. The glands were immediately removed from the experimental animals euthanized by cervical dislocation. After 3, 6 and $24 \mathrm{~h}$, three mice from each group were ready for adrenal gland removal. Samples were sliced at $1 \mathrm{~mm}$ thickness, and prefixed at $40^{\circ} \mathrm{C}$ in $2.5 \%$ glutaraldehyde in phosphate buffer saline (PBS) for $2 \mathrm{~h}$. Then, they were washed twice in cold PBS for $10 \mathrm{~min}$, and post-fixed in cold $1 \%$ osmium tetraoxide in PBS for $2 \mathrm{~h}$. Specimens were washed three times in cold distilled water, stained with $1 \%$ uranyl acetate, dehydrated in a sequences of alcohol, and embedded in epoxy LX-112 (Ladd Research Inc. USA) resin. Ultrathin sections were cut and stained with uranyl acetate and lead citrate. Samples were observed with a FEI, TecnaiSpirit 12G2 model transmission electron microscope, with an accelerating voltage of $100 \mathrm{kV}$.

Study variables on the adrenal gland cortex (quantitative study). For the descriptive study of mitochondria from adrenal cortex micrograph, the registration and the magnification factor revealing the physical image was used. The images obtained directly from the electron microscope included and maintained the size, according to the original increase obtained.

The estimated variables for the quantitative description of the mitochondria in the adrenal gland cortex were: 1) Number of mitochondria; 2) Area of the mitochondria; 3) Number of mitochondrial cristae per mitochondrial unit.

\section{Analysis and description of the samples}

Observation. The frames were presented with the sample previously contrasted with the transmission electron microscope. The technological equipment used for this work was the FEI Quanta 250 FEG microscope in STEM mode.

Digitisation of the Image. The biological systems observation from a micrograph was used for the graphical study. The images obtained directly from the electron microscope were comprised, and maintained the size according to the initial increase, with which it was attained. The images obtained by the FEI Quanta 250 FEG were stored digitally in a computer for further study.

\section{Numerical handling of the results}

Imagine J. Morphometric measurements were carried out from the micrographs obtained in the thin and thick sections by using an IMAGE J program (National Institutes of Health, USA). 
Analysis of Variance (ANOVA). The ANOVA is a statistical procedure that allows analysing if more than two groups diverge considerably among themselves, in terms of their means and variance. The method for comparing these values is based on the global variance observed in the groups of numerical data, to be compared. Typically, the ANOVA was

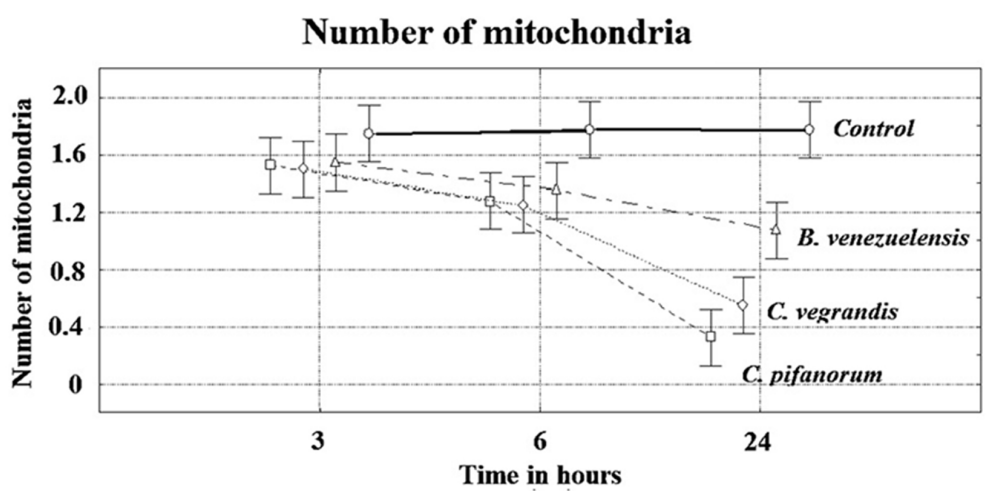

Fig. 1. Quantitative analysis of mitochondria number under Viperidae venom action. To estimation of the number of mitochondria, per square micrometre $\left(\mu \mathrm{m}^{2}\right)$ after 3, 6 and 24 hours of treatments with snake venom. An analysis of variance (ANOVA) of two factors at $95 \%$ confidence was developed, in which it was found that there were significant differences in treatments (factor 1) $\mathrm{P}=$ 0.00 and significant difference for times (factor 2) $\mathrm{P}=0.00$, with an interaction of $\mathrm{P}=0.00$. The graph shows the trends of the means and standard deviations, for the 4 treatments over time, obtained during the study of the number of mitochondria per square micrometre.

Table I. Quantitative analysis of mitochondria number under Viperidae venom action. The averages and the standard deviation of the study of the number of mitochondria per square micrometre $\left(\mu \mathrm{m}^{2}\right)$, after 3, 6 and 24 hours of treatments with snake venom are shown. The letters $a, b, c, d, e, f, g$ are derived from a posteriori lowest statistically detectable difference test (SDD), in which the groups, that have important differences among their means are assigned different letters, in alphabetical order, defining the groups of higher means with the letter a, and as its average significantly decreases, it is consigned and represented by another letter (a to g) (Angst et al., 2001).

\begin{tabular}{lccc}
\hline Species & Time in hours & Means \pm SD & \\
\hline Crotalus pifanorum & 3 & $1.55 \pm 0.090$ & $\mathrm{abc}$ \\
& 6 & $1.30 \pm 0.107$ & $\mathrm{bcd}$ \\
Crotalus vegrandis & 24 & $0.36 \pm 0.080$ & $\mathrm{e}$ \\
& 3 & $1.50 \pm 0.080$ & $\mathrm{abc}$ \\
Bothrops venezuelensis & 6 & $1.25 \pm 0.093$ & $\mathrm{~cd}$ \\
& 24 & $0.55 \pm 0.107$ & $\mathrm{e}$ \\
& 3 & $1.59 \pm 0.040$ & $\mathrm{ab}$ \\
Control & 6 & $1.32 \pm 0.010$ & $\mathrm{bcd}$ \\
& 24 & $1.06 \pm 0.109$ & $\mathrm{~d}$ \\
& 3 & $1.72 \pm 0.120$ & $\mathrm{a}$ \\
& 6 & $1.75 \pm 0.124$ & $\mathrm{a}$ \\
& 24 & $1.75 \pm 0.126$ & $\mathrm{a}$ \\
\hline
\end{tabular}

SDD: smallest statistically detectable difference test. SD: standard deviation.
Principal Components Analysis (PCA). The principal component analysis (PCA) consists of expressing a set of variables in an ensemble of linear combinations of factors, which are not correlated with each other. This method allowed representing the original data (individuals and variables), in a space of fewer dimensions than the original space.

Smallest statistically detectable difference test (SDD). This test was performed relating the statistical values obtained by Viperidae venoms mitochondria treatment, with those found in the control treatment. The letters a, b, c, d, e, f, g were resulting from a posteriori smallest statistically detectable difference test (SDD) (Angst et al., 2001).

\section{RESULTS}

Amongst the quantitative changes in the mitochondria, when the three venoms of the different snakes were tested, a decrease in their number was observed. The alterations present in both venoms from Crotalus genus were very similar between them, as well as for the $B$. venezuelensis during 3 and $6 \mathrm{~h}$ post injection (Fig.1). However, the three venom species did not have statistically significant differences at 3 and $6 \mathrm{~h}$ post venom injection (Table I).

On the other hand, at $24 \mathrm{~h}$ post injection, the number of mitochondria showed significant differences between the groups injected with Crotalus and B. venezuelensis venoms. A smaller number of mitochondria were observed with Crotalus venoms (Table I).

Regarding the mitochondrial area, after $3 \mathrm{~h}$ of venom injections, the three species studied did not show significant differences as compared with the normal control, thus indicating that initially there were no changes in the area of the mitochondria (Fig. 2 and Table II). 
Past $6 \mathrm{~h}$ post injection with venom, an increase in the mitochondrial area could be appreciated, in which $C$. vegrandis did not present significant differences with $C$. pifanorum or $B$. venezuelensis, however, these last two showed statistically significant differences among them (Table II).

\section{Area of the Mitochondria}

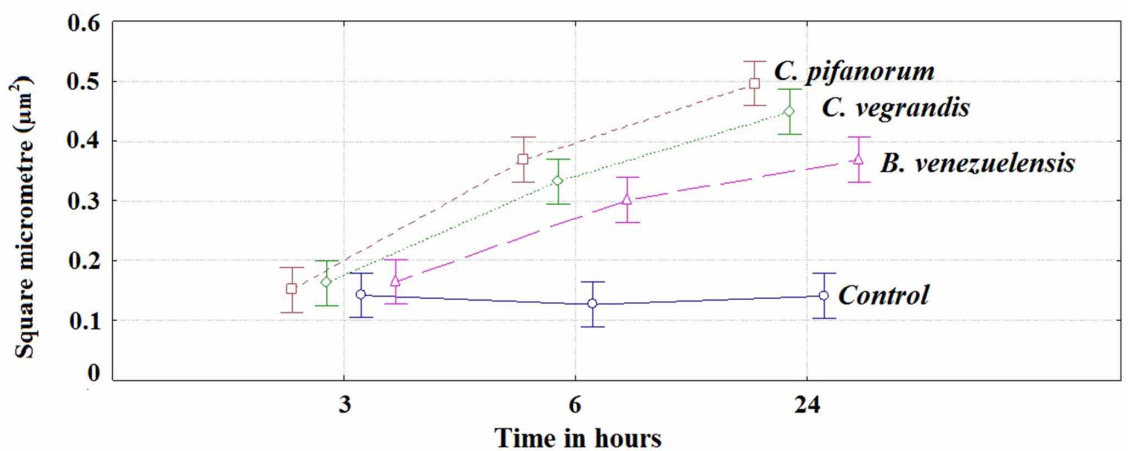

Fig. 2. Quantitative analysis of the mitochondria area under Viperidae venom action. Assessment of the mitochondrial area per square micrometre $\left(\mu \mathrm{m}^{2}\right)$ after 3,6 and 24 hours of treatments with snake venoms. An analysis of variance (ANOVA) of two factors at $95 \%$ confidence was elaborated, in which it was found that there were significant differences for the changes in the treatments (factor 1 ) $\mathrm{P}=0.00$ and significant difference, for the times (factor 2) $\mathrm{P}=0.00$, with an interaction of $\mathrm{P}=0.00$. The graph shows the trends of the means and standard deviation, for the 4 treatments obtained over time, during the study of the mitochondria area.

Table II. Quantitative analysis of the mitochondria area under Viperidae venom action. The averages and the standard deviation of the study of the mitochondria area per square micrometre $\left(\mu \mathrm{m}^{2}\right)$, after 3, 6 and 24 hours of treatments with snake venom are shown. The letters a, b, c, d, e, f, g are derived from a posteriori lowest statistically detectable difference test (SDD), in which the groups, that have important differences among their means are assigned different letters, in alphabetical order, defining the groups of higher means with the letter a, and as its average significantly decreases, it is consigned and represented by another letter (a to g) (Angst et al., 2001).

\begin{tabular}{lccc}
\hline Species & Time in hours & \multicolumn{2}{c}{ Means \pm SD SDD } \\
\hline Crotalus pifanorum & 3 & $0.13 \pm 0.008$ & $\mathrm{~d}$ \\
& 6 & $0.35 \pm 0.020$ & $\mathrm{~b}$ \\
Crotalus vegrandis & 24 & $0.49 \pm 0.029$ & $\mathrm{a}$ \\
& 3 & $0.16 \pm 0.011$ & $\mathrm{~d}$ \\
Bothrops venezuelensis & 6 & $0.33 \pm 0.020$ & $\mathrm{bc}$ \\
& 24 & $0.45 \pm 0.029$ & $\mathrm{a}$ \\
& 3 & $0.18 \pm 0.019$ & $\mathrm{~d}$ \\
Control & 6 & $0.28 \pm 0.030$ & $\mathrm{c}$ \\
& 24 & $0.36 \pm 0.019$ & $\mathrm{~b}$ \\
& 3 & $0.13 \pm 0.009$ & $\mathrm{~d}$ \\
& 6 & $0.15 \pm 0.009$ & $\mathrm{~d}$ \\
& 24 & $0.14 \pm 0.007$ & $\mathrm{~d}$ \\
\hline
\end{tabular}

SDD: smallest statistically detectable difference test. SD: standard deviation.
Past 24 h of venom injections, no significant differences were observed between the two species of the Crotalus genus, and there was an increase of the mitochondrial area up to $100 \%$ post-injection (Fig. 2 and Table II). When comparing these results with those obtained for the Bothrops venom, it was observed that the Crotalus venom species had the highest rate of the mitochondrial area increase compared with the normal control.

Twenty-four hours post venom injection, there were no significant differences in the decrease of the number of mitochondrial cristae those those injected with the venom of Crotalus species. However, comparing these data with the one obtained for the case of the $B$. venezuelensis venom, it was found that both genera of snake venoms presented significant differences. The Crotalus genus species presented a lesser number of those that presented smaller number of mitochondrial cristae and consequently, higher alterations (Table III).

Observing the qualitative features in the adrenal gland cortex normal control, mitochondria were observed with their tubular cristae, the inner boundary membrane, the outer membrane, and the smooth endoplasmic reticulum (Fig.4).

On the other hand, the adrenal gland cortex mitochondria after $3 \mathrm{~h}$ of $C$. vegrandis venom injection showed: A) An irregular thickness of the intermembrane space in the mitochondria, whereas the internal membrane could not be seen in some areas. The arrangement of the cristae looked somewhat irregular. B) In these mitochondria, again the intermembrane space was not uniform, neither were the inter-cristae. C) The 
space between the membranes was narrowed and electron dense, suggesting initiation of autophagy. The arrangement of the cristae was irregular. Past $6 \mathrm{~h}$ post venom injections: A) the electrondensity of the inter-membrane area suggested initiation of autophagy. B) The space between the membranes was not uniform

\section{Number of mitochondria cristae}

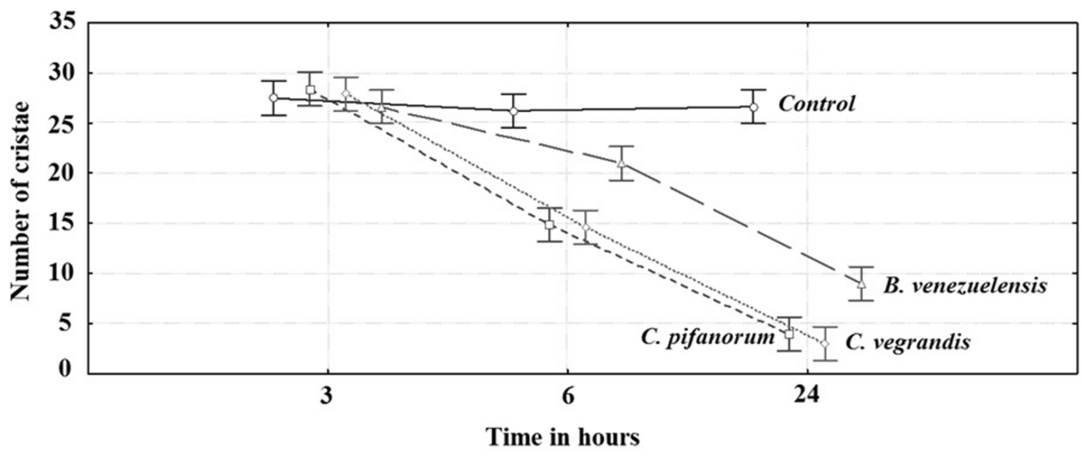

Fig. 3. Quantitative analysis of the number of mitochondrial cristae under B. venezuelensis venom activities action. Evaluation of the number of mitochondrial cristae per mitochondria after 3, 6 and 24 hours of treatments with snake venom. An analysis of variance (ANOVA) of two factors at $95 \%$ confidence was elaborated in which it was found that there were significant differences for the changes in the treatments (factor 1) $\mathrm{P}=0.00$ and significant difference for the times (factor 2) $\mathrm{P}=0.00$ with an interaction of $\mathrm{P}=0.00$. The figure shows the trends of the means and standard deviation, for the 4 treatments over time. obtained during the study of the number of mitochondrial cristae per mitochondria.

Table III. Quantitative analysis of the number of mitochondrial cristae under Viperidae venom action. The averages and the standard deviation of the study of the mitochondria cristae number per mitochondria, after 3, 6 and 24 hours of treatments with snake venom are showed. The letters a, b, c, d, e, f, g are derived from a posteriori lowest statistically detectable difference test (SDD), in which the groups, that have important differences among their means are assigned different letters, in alphabetical order, defining the groups of higher means with the letter a, and as its average significantly decreases, it is consigned and represented by another letter (a to g) (Angst et al., 2001).

\begin{tabular}{lccc}
\hline Species & Time in hours & \multicolumn{2}{c}{ Means \pm SD } \\
& & SDD & \\
\hline Crotalus pifanorum & 3 & $27.49 \pm 0.80$ & $\mathrm{a}$ \\
& 6 & $15.01 \pm 0.89$ & $\mathrm{c}$ \\
Crotalus vegrandis & 24 & $27.01 \pm 0.39$ & $\mathrm{e}$ \\
& 3 & $14.60 \pm 0.99$ & $\mathrm{a}$ \\
& 6 & $3.00 \pm 0.43$ & $\mathrm{e}$ \\
Bothrops venezuelensis & 24 & $27.01 \pm 0.79$ & $\mathrm{a}$ \\
& 3 & $21.05 \pm 0.78$ & $\mathrm{~b}$ \\
Control & 6 & $8.87 \pm 0.87$ & $\mathrm{~d}$ \\
& 24 & $27.06 \pm 0.74$ & $\mathrm{a}$ \\
& 3 & $27.26 \pm 1.08$ & $\mathrm{a}$ \\
& 6 & $26.98 \pm 0.80$ & $\mathrm{a}$ \\
\hline
\end{tabular}

SDD: smallest statistically detectable difference test. SD: standard deviation. and the cristae were swollen. C) Mitochondrial envelope areas were lost. At $24 \mathrm{~h}$ post venom injections: A) mitochondria were presented without cristae and swollen matrix. B) Myelin figure formation from a mitochondrion was noticed. C) The integrity of the mitochondria was lost. The matrix looked swollen (Fig. 5).

The adrenal gland cortex mitochondria after $3 \mathrm{~h}$ of $C$. pifanorum venom injection showed: A) Autophagy and a space between the membranes of different thickness. The cristae lost their integrity. B) Areas with loss of the internal membrane and in some places of both membranes were noticed. C) A swelling of the intermembrane space and in certain places the membranes look interrupted. At $6 \mathrm{~h}$ post venom injection: A) There was damage of limiting membranes and vacuolisation in the matrix. B) Remains of the mitochondria surrounded by RER cisternae, suggesting a previous energetic relationship was seen. C) The loss of the mitochondrial envelope was observed. At $24 \mathrm{~h}$ post venom injection: A) An increase in inter-membrane space and in the electrondensity of the matrix was observed, suggesting an autophagic process. B) Rupture of the mitochondrial envelope and disappearance of cristae was observed. C) Cristae and matrix looked swollen. Ruptures of mitochondria membranes in large area were seen (Fig. 6).

The adrenal gland cortex mitochondria after $3 \mathrm{~h}$ of $B$. venezuelensis venom injection showed: $\mathrm{A}$ ) Swollen cristae and matrix. B) Decrease in the number of cristae. C) Interruptions between the membranes. At 6 h: A) Loss of the mitochondrial envelope was observed. B) The formation of a myelin figure from the residues of mitochondria was observed. C) Partial loss of the mitochondrial envelope was seen. At 24 h: A) Areas with loss of the inner membrane and decrease of cristae were noticed. B) Rupture of the mitochondrial envelope and swelling of the matrix was observed. C) Partial loss of the mitochondrial cover was seen (Fig. 7). 


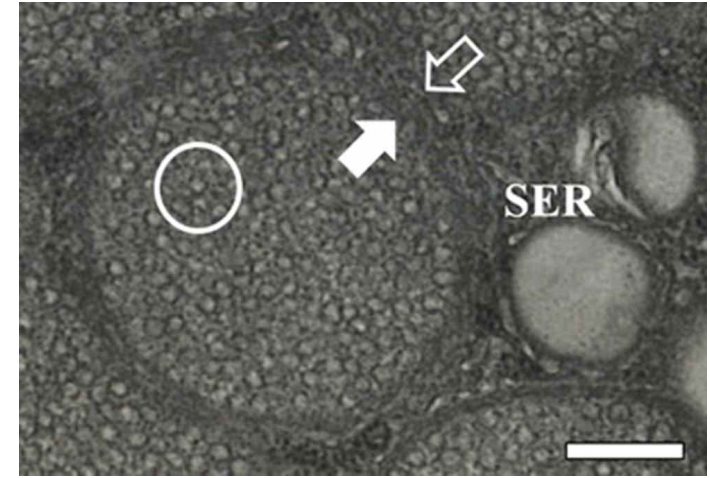

Fig. 4. Normal control mitochondria. Cristae (circle); the inner boundary membrane (full arrow); Outer membrane (empty arrow). Smooth endoplasmic reticulum (SER). Micromark = $200 \mathrm{~nm}$.
$3 \mathrm{~h}$

A

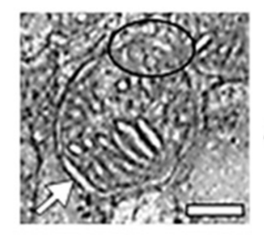

A

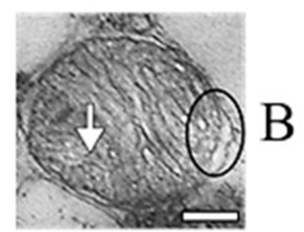

$6 \mathrm{~h}$
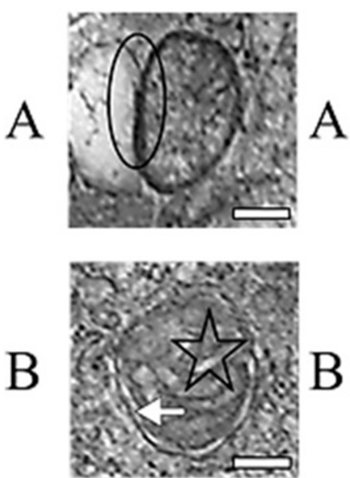

$24 \mathrm{~h}$

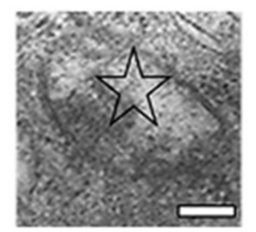

$B$

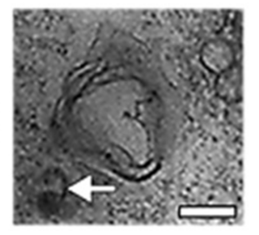

Fig. 5. Adrenal cortex mitochondria from mice treated with C. vegrandis venom. After $3 \mathrm{~h}$ of venom injection: A) The mitochondria showed an irregular thickness of the intermembrane space (arrow), and the internal membrane cannot be seen in some areas (oval). The arrangement of the cristae looks somewhat irregular. B) In this mitochondria, again the inter-membrane space was not uniform (oval), neither is the inter-cristae (arrow). C) The space between the membranes narrowed and electron dense (oval), suggesting initiation of autophagy. The arrangement of the cristae was irregular. After $6 \mathrm{~h}$ of venom injection: A) The electron density of the inter-membrane area suggesting autophagy (oval). B) The space between the membranes was not uniform (arrow) and the cristae were swollen (star). C) Mitochondrial envelope areas lost (oval). After $24 \mathrm{~h}$ of venom injection: A) Mitochondria were presented without cristae and swollen matrix (star). B) Myelin (Arrow) formation from mitochondria was noticed. C) The integrity of the mitochondria was lost. The matrix looks swollen (oval). Micromark $=200 \mathrm{~nm}$.

Fig. 6. Adrenal cortex mitochondria from mice treated with $C$. pifanorum venom. After $3 \mathrm{~h}$ of $C$. pifanorum venom injection showed: A) Autophagy (star). A space between the membranes of different thickness was observed (arrow). The cristae lost their integrity (oval). B) Areas with loss of the internal membrane and in some places of both membranes (arrows). C) A swelling of the inter-membrane space (arrow) and in certain places the membranes look interrupted (oval). At $6 \mathrm{~h}$ : A) There was loss of limiting membranes (arrow) and vacuolisation in the matrix (star). B) Remains of the mitochondria surrounded by a RER cisternae (arrow), suggesting a previous energetic relationship was seen. C) The loss of the mitochondrial envelope was observed (arrows). At $24 \mathrm{~h}$ : A) Swollen of the outer membrane (arrow) and decrease of cristae were noticed (star). B) Rupture of the mitochondrial envelope (arrows) and disappearance of cristae was observed (star). C) Cristae and matrix look swollen (star). Rupture of mitochondria membranes in large area was seen (oval). Micromark $=200 \mathrm{~nm}$. 
$3 \mathrm{~h}$

A
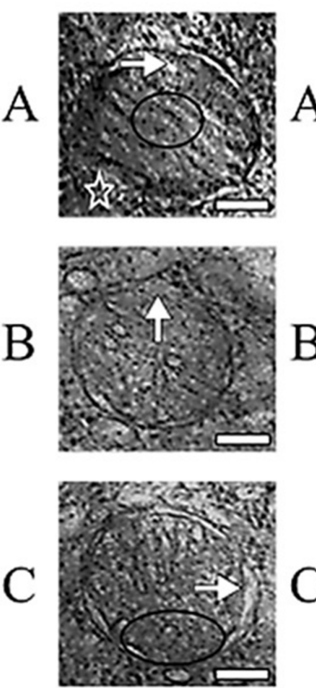

Fig. 7. Adrenal cortex mitochondria from mice treated with B. venezuelensis venom. After $3 \mathrm{~h}$ of $\mathrm{B}$. venezuelensis venom injection showed: A) Cristae and matrix looked swollen (star). B) Decrease in the number of cristae was noticed (oval). C) Interruptions between the membranes was detected (arrows). At 6 h: A) Loss of the mitochondrial envelope was observed (arrows). B) The formation of a myelin figure, from the residues of a mitochondria was observed (oval). C) Partial loss of the mitochondrial envelope is seen (arrows). At $24 \mathrm{~h}$ : A) Areas with loss of the inner membrane (arrow) and decrease of cristae were noticed (oval). B) Rupture of the mitochondrial envelope (arrows) and swelling of the matrix was observed (star). C) Partial loss of the mitochondrial cover was seen (arrow) and swelling of the matrix was observed (oval). Micromark $=200 \mathrm{~nm}$.

\section{DISCUSSION}

Transmission electron microscopy studies describing the alterations caused by snake venoms in several organs are infrequent, mainly as regarding the adrenal gland. This showed the way to study the mice adrenal gland alterations produced by Viperidae snake venoms (Crotalus Bothrops genera). This organ is vital for the mammalian homeostasis processes, such as the synthesis of hormones, blood glucose concentration control and renal filtration, among others (Selyatitskaya et al., 2008).

It is known that the snake venom effects occur in a short period of time, producing a high rate of early damage in victims (Rengifo \& Rodríguez-Acosta, 2004). Here, it is intended to present the damages caused by the venoms that take place in the mitochondria at variable times, creating kinetics of the approximate time, in which the mitochondrial ultrastructural alterations occurred. To show these impairments, 3, 6 and $24 \mathrm{~h}$ post venom injection times were taken into account.
In the qualitative observations it was possible to see intense damages, with loss and swelling of membranes, disappearance of cristae, and appearance of myelin, which attested previous destruction of mitochondria, which appeared after $3 \mathrm{~h}$ of the Crotalus and Bothrops venom injections.

The adrenal gland is a highly irrigated organ by the superior adrenal artery (Pró, 2014), where capillaries circulate through the adrenal cortex and anastomoses forming a plexus outside the medulla. This large blood flow contributes to the regulation of the adrenal function, and also makes the gland a suitable target for the action of proteolytic enzymes present in snake venoms. The venom toxins are able to modify (increase) vascular permeability (normally high, given the function of secretion of the adrenal gland), allowing the extravasation of compounds, capable of altering the ultrastructure of organelles, such as the mitochondria (Bottrall et al., 2011).

There is a difference between Crotalus and Bothrops envenomation, possibly related to the toxic mechanism present in venoms. Rattlesnake (Crotalus) venom contains a variety of peptides, enzymes and toxins such as the crotoxin, a toxin that creates an effect of intense muscular damage and bleeding blocking platelet aggregation (Hati et al., 1999) or crotamine that has cytotoxic effects (Sánchez et al., 2018). Also there are metalloproteases and phospholipases acting on capillary endothelial cells (Avila-Agüero et al., 1999; Hernández et al., 2006), which cause haemorrhages in many organs, including the adrenal glands (Yeh et al., 2001).

These two completely different effects may seem counterproductive, however, the effect is additive. Firstly, if the endothelial cells are broken, it will cause a lysis and an internal bleeding effect, which would explain the capillary alterations. Then these haemorrhages increase the natural response of thrombin, which is hampered by the effect of the crotoxin, increasing its toxic effects on subcellular structures such as mitochondria.

The alterations observed by Bothrops are due to haemorrhagic metalloproteinase and the coagulant serine proteases (Girón et al., 2013). The venom also contains between 15 and 20 enzymes, among them, phospholipases, hyaluronidases, monophosphoesterases, acetylcholinesterases, and thrombolytic enzymes, which act by modifying the capillary permeability, causing necrosis of the affected tissues, and its subcellular components, including the mitochondria (Lackner, 2013). Therefore, all these toxic activities of both Crotalus and 
Bothrops have their direct or indirect action on all the mitochondria integrity, causing damage to their membranes, or producing necrotic effects by these toxins.

Mitochondria remain a fascinating sub-cellular structure because of their distinctive roles in countless cellular activities. By using an electron microscope, it is simple to differentiate mitochondria presenting double membranes and characteristic inner compartmentalization from other intracellular organelles, such as peroxisomes, which present a single membrane with fine structure without cristae and a dense crystalloid core (Vakifahmetoglu-Norberg et al., 2017). In Fig. 4, a normal mitochondria control is shown, presenting cristae, internal and external membranes and close to the mitochondria, two tubules, which are SER elements. The inner membrane consists of two domains: the inner boundary membrane adjacent to the outer membrane and invaginations, which in most cells has the form of cristae, which are connected by tubular openings, called cristae junctions.

Mitochondria are extremely active organelles that rise in number by division during the interphase, but, remain autonomous from the cell cycle. They develop actions of fusion and fission, which are essential for the preservation of regular mitochondrial structures and functions. Mitochondria are susceptible to cellular disturbance and have a crucial responsibility in the origination of programmed cell death. The apoptotic changes of the cell are generally produced by the cytochrome $\mathrm{C}$ liberation from the inter-membrane space into the cytoplasm, initiating the cascade of proteolytic reactions.

This study proposed that most of the alterations were sublethal, and acted by decreasing the production of energy damaging the mitochondria, which regulates the oxidative processes. Knowing that mitochondria possess the necessary enzymes for the conversion of cholesterol into the steroids excreted by the adrenal gland, including cortisol, the mitochondrion is a valuable organelle in the elucidation of the cellular failures and ultrastructural changes that appear after the snake venom injection.

The quantitative results would not necessarily indicate that the venom of $B$. venezuelensis is less potent that the Crotalus species. It is also known that the mitochondrial necrosis processes had been observed with other Bothrops venom (Zárraga et al., 2003).

Ultrastructural irregularities of mitochondria have been known to be frequently caused by drug toxicity (alcohol, hydrazine) involving diverse pathogenic processes. Additionally, it has been proposed that the risk of developing Parkinson Disease is increased by exposure to toxins, such as rotenone, that similarly affect mitochondrial respiratory complex I (Ascherio \& Schwarzschild, 2016). These abnormalities comprise not only an escalation of the number of mitochondria, but similarly a distended and anomalous form, differences in the number of cristae and specific arrangements of cristae, and unusual inclusions (Lindal et al., 1992).

The alterations produced in the mitochondria, such as the decrease in their number, the mitochondrial area and the number of mitochondrial cristae, could indicate a reduction in the metabolic rate, due to the envenoming from the three species of snakes studied. Exceptions have been registered, particularly in rapidly metabolically active tissues, in which the mitochondria can be large or small and have or lack of cristae. These details agree with the analysis presented here, since the number of mitochondrial cristae per mitochondrion and the numbers of mitochondria per unit area were apparently unrelated. The thesis that the amount of mitochondria is reduced in different pathologies was supported by biochemical studies, which observed this phenomenon in hepatocytes, due to low respiratory capacity (Emmelot et al., 1959). Such a metabolic restriction would not only imply a decrease in the secretion of cortisol, and other corticosteroids, but a decrease in the concentration of aldosterone. When the secretion of aldosterone is minimal, large amounts of salt are lost in the urine, decreasing not only the sodium chloride content in the extracellular fluid, but also its volume. As a result, intense cellular dehydration occurs, which may lead to death in a few days if it is not treated quickly (Azizi et al., 2013).

Even though in numerous cells mitochondria seem to be randomly dispersed in the cytoplasm, there are evidences showing the association between mitochondria and other organelles. Such relations are reasonably characteristic, and offer sufficient patterns of the connection between structure and function. Numerous interpretations indicate that mitochondria are often located near supplies of substrates, or at recognised places inside the cells that need ATP produced by the mitochondria (Nelson \& Cox, 2017).

The function of the mitochondria-ribosome complex is not very clear, but the proximity between them suggests an increase in the synthesis of many proteins related to the cellular mechanisms of defence, under stress conditions. Mitochondrial degeneration has also been reported (Rodríguez-Acosta et al., 1999) in mouse hepatocytes, experimentally injected with rattlesnake venom.

In conclusion, the current work shows a varied array of effects caused by Viperidae venom activities, which act on the mitochondria, altering their morphology and number. It seems that these modifications are primarily triggered by the venom proteases and phospholipases, but not eliminating other venom constituents, for instance, some enzymes and/ 
or non-enzymatic toxins and peptides that could similarly deliver these effects.

This preliminary study covers the route for the recognition that molecules in Viperidae venoms that may explain the phenomena of adrenal gland failure in these ophidic accidents.

\section{FUNDING AND ACKNOWLEDGEMENTS}

This research did not receive any specific grant from funding agencies in the public, commercial, or not-for-profit sectors. We would like to thank Veronica Rodriguez-Pulido (M.A) for the manuscript English revision and to express our sincere gratitude to the employees of the Pharmacy Faculty Serpentarium of the Universidad Central de Venezuela.

FINOL, H. J.; GARCÍA, E.; GONZÁLEZ, R.; SANCHEZ, E. E. \& RODRÍGUEZ-ACOSTA, A. Análisis ultrastructural cualitativo y cuantitativo de la mitocondria de la glándula adrenal bajo la acción de los venenos de serpientes de la familia Viperidae. Int. J. Morphol., 38(5):1271-1280, 2020.

RESUMEN: Los venenos de Viperidae tienen acciones enzimáticas y no enzimáticas, que actúan sobre la estructura celular. Aquí se probaron, a las 3, 6 y 24 horas de la inyección del veneno, el número de mitocondrias, el área mitocondrial y el número de crestas mitocondriales de la corteza de las glándulas adrenales. Los cambios cuantitativos de las mitocondrias mostraron una disminución en el número de mitocondrias a las 3, 6 y 24 h. Hubo un aumento en el área mitocondrial a las $6 \mathrm{~h}$, donde el veneno de la serpiente Crotalus vegrandis no presentó diferencias significativas con los venenos de Crotalus pifanorum o Bothrops venezuelensis. Después de $24 \mathrm{~h}$, hubo un aumento del área mitocondrial en todos los venenos. El número de crestas mitocondriales a las $3 \mathrm{~h}$ no presentó alteraciones o diferencias importantes con el tratamiento de control. Después de $6 \mathrm{~h}$, el número de crestas mitocondriales comenzó a disminuir bajo la acción de los 3 venenos, hasta las 24 h de observación. En las observaciones cualitativas se observó un daño intenso de las mitocondrias, con pérdida y edema de las membranas, desaparición de las cristae y aparición de figuras mielínicas, que comenzó a las $3 \mathrm{~h}$ después de las inyecciones de veneno de Crotalus y Bothrops. Estos daños se debieron factiblemente a los efectos citotóxicos de componentes proteolíticos de los venenos. Creemos que estos resultados definen un nuevo y original hallazgo, que sugiere que los venenos de serpiente Viperidae son extremadamente tóxicos para las mitocondrias de mamíferos.

PALABRAS CLAVE: Bothrops venezuelensis; Cristae; Crotalus pifanorum; Crotalus vegrandis; Glándula adrenal; Mitocondria; Veneno.

\section{REFERENCES}

Angst, F.; Aeschlimann, A. \& Stucki G. Smallest detectable and minimal clinically important differences of rehabilitation intervention with their implications for required sample sizes using WOMAC and SF-36 quality of life measurement instruments in patients with osteoarthritis of the lower extremities. Arthritis. Rheum., 45 (4):384-91, 2001.

Ascherio, A. \& Schwarzschild, M. A. The epidemiology of Parkinson's disease: risk factors and prevention. Lancet. Neurol., 15(12):1257-72, 2016.

Avila-Agüero, M. L. Nuevos conceptos en el manejo de los pacientes pediátricos mordidos por serpientes venenosas. Acta. Pediátr. Costarric., 13(3):140-90, 1999.

Azizi, M.; Amar, L. \& Menard, J. Aldosterone synthase inhibition in humans. Nephrol. Dial. Transplant., 28(1):36-43, 2013.

Bottrall, J. L.; Madaras, F.; Biven, C.; Venning, M. \& Mirtschin, P. J. Proteolytic activity of Elapid and Viperid Snake venoms and its implication to digestion. J. Ven. Res., 1(1):18-28, 2011.

Cho, Y. M.; Kwon, S.; Pak, Y. K.; Seol, H. W.; Choi, Y. M.; Park, D. J.; Park, K. S. \& Lee, H. K. Dynamic changes in mitochondrial biogenesis and antioxidant enzymes during the spontaneous differentiation of human embryonic stem cells. Biochem. Biophys. Res. Com., 348(4):1472-8, 2006.

Emmelot, P.; Bos, C. J.; Brombacher, P. J. \& Hampe, J. F. Studies on isolated tumour mitochondria: biochemical properties of mitochondria from hepatomas with special reference to a transplanted rat hepatoma of the solid type. Br. J. Cancer., 13(2):348-79, 1959.

Girón, M. E.; Guerrero, B.; Salazar, A. M.; Sánchez, E. E.; Alvarez, M. \& Rodríguez-Acosta, A. Functional characterization of fibrinolytic metalloproteinases (colombienases) isolated from Bothrops colombiensis venom. Toxicon, 74:116-26, 2013.

Hati, R.; Mitra, P.; Sarker, S. \& Bhattacharyya, K. K. Snake venom hemorrhagins. Crit. Rev. Toxicol., 29(1):1-19, 1999.

Hernández, M.; Scannone, H.; Finol, H. J.; Pineda, M. E.; Fernandez, I.; Girón, M. E. \& Rodriguez-Acosta, A. The crotoxin activity of rattlesnake venom (Crotalus durissus cumanensis) on the ultrastructure of cardiac atrial muscle. Arch. Ven. Med. Trop., 4(1):15-21, 2006.

Lackner, L. L. Determining the shape and cellular distribution of mitochondria: the integration of multiple activities. Curr. Opin. Cell. Biol., 25(4):471-6, 2013.

Lebowitz, M. S. \& Pedersen, P. L. Protein inhibitor of mitochondrial ATP synthase: Relationship of inhibitor structure to $\mathrm{pH}$-dependent regulation. Arch. Biochem. Biophys., 330(2):342-54, 1996.

Lindal, S.; Lund, I.; Torbergsen, T.; Aasly, J.; Mellgren, S. I. Borud, O. \& Monstad, P. Mitochondrial diseases and myopathies: a series of muscle biopsy specimens with ultrastructural changes in the mitochondria. Ultrastruct. Pathol., 16(3):263-75, 1992.

Milton, J. S. Estadística para Biología y Ciencias de la salud. $5^{\text {th }}$ ed. Madrid, Mc Graw-Hill/ Interamericana, 2001. pp 1-1294

Nelson, D. L. \& Cox, M. M. Lehninger Principles of Biochemistry. $7^{\text {th }}$ Edition, USA, Macmillan, pp.1-1294, 2017.

Pifano, F. Investigación y docencia en Medicina Tropical. Arch. Ven. Med. Trop. Parasitol. 4(1):1-203, 1961.

Pró, E. Anatomía Clínica. México, Medica Panamericana, pp. 1-100, 2014.

Rengifo, C. \& Rodríguez-Acosta, A. Serpientes, veneno y tratamiento médico en Venezuela. Caracas, Universidad Central de Venezuela. Fondo Editorial de la Facultad de Medicina, 2004.

Rodríguez-Acosta, A.; Pulido, M.; Finol, H.; Girón, M. \& Aguilar, I. Liver ultrastructural pathology in mice envenomed with Uracoan rattlesnake Crotalus vegrandis venom. J. Submicrosc. Cytol. Pathol., 31(3):433-9, 1999.

Rodríguez-Acosta, A.; Strauss, M.; Pulido-Mendez, M. \& Finol, H. J. Adrenal gland ultrastructural changes in mice inoculated with Tityus discrepans (Buthidae) venom. Rev. Cient. FCV-LUZ, 10(6): 480-5, 2000. 
FINOL, H. J.; GARCÍA, E.; GONZÁLEZ, R.; SANCHEZ, E. E. \& RODRÍGUEZ-ACOSTA, A. Qualitative and quantitative ultrastructural analysis of the mitochondria from adrenal gland cortex under the action of Viperidae family snake venoms. Int. J. Morphol., 38(5):1271-1280, 2020.

Rodriguez-Acosta, A.; Vega, J. L.; Finol, H. J. \& Pulido-Mendez, M. Ultrastructural alterations in cortex of adrenal gland caused by the toxic effect of bee (Apis mellifera) venom. J. Submicrosc. Cytol. Pathol., 35(3):309-14, 2003.

Sánchez, E. E.; Girón, M. E.; Uzcátegui, N. L.; Guerrero, B.; Saucedo, M.; Cuevas, E. \& Rodríguez-Acosta, A. Biochemical and biological characterisation of lancehead (Bothrops venezuelensis Sandner 1952) snake venom from the Venezuelan Central Coastal Range. Bol. Malariol. Sal. Amb., 54(2):138-49, 2014.

Sánchez, E. E.; Gonzalez, R.; Lucena, S.; García, E.; Finol, H. J.; Suntravat, M.; Girón, M. E.; Fernandez, I. \& Rodriguez-Acosta, A. Crotaminelike from Southern Pacific rattlesnake (Crotalus oreganus helleri) venom acts on human leukemia (K-562) cell lines and produces ultrastructural changes on mice adrenal gland. Ultrastruct. Pathol., 42(2):116-23, 2018.

Selyatitskaya, V. G.; Cherkasova, O. P.; Pankina, T. V. \& Palchikova, N. A. Functional state of adrenocortical system in rats with manifest alloxaninduced diabetes mellitus. Bull. Exp. Biol. Med., 146(6):708-10, 2008.

Sotelo, N. Envenenamiento por mordedura de serpiente de cascabel, daños a la salud y su tratamiento en edad pediátrica. Gac. Med. México, 4: 21-39, 2003.

Vakifahmetoglu-Norberg, H.; Ouchida, A. T. \& Norberg, E. The role of mitochondria in metabolism and cell death. Biochem. Biophys. Res. Commun., 482(3):426-31, 2017.

Waring, A. J.; Rottenberg, H.; Ohnishi, T. \& Rubin, E. The effect of chronic ethanol consumption on temperature-dependent physical properties of liver mitochondrial membranes. Arch. Biochem. Biophys., 216(1):5161, 1982.

Yeh, C. H.; Chang, M. C.; Peng, H. C. \& Huang, T. F. Pharmacological characterization and antithrombotic effect of agkistin, a platelet glycoprotein Ib antagonist. Br. J. Pharmacol,. 132(4):843-50, 2001.

Zárraga, A.; Velásquez, L.; Strauss, M. \& Rodríguez-Acosta, A. Notes about subcellular testicular changes induced by the venom of South American mapanare Snake (Bothrops colombiensis). Rev. Cient. FCV-LUZ, 13(6): 436-9, 2003.
Corresponding author:

Alexis Rodríguez-Acosta

Laboratory of Immunochemistry and Ultrastructure

Anatomical Institute

Universidad Central de Venezuela

Caracas

VENEZUELA

Email: rodriguezacosta1946@yahoo.es

Received: 08-03-2020

Accepted: 03-05-2020 